\title{
Adjuvant chemotherapy with irinotecan hydrochloride and cisplatin for clear cell carcinoma of the ovary
}

\author{
MASASHI TAKANO ${ }^{1,13}$, YOSHIHIRO KIKUCHI ${ }^{1}$, NOBUO YAEGASHI ${ }^{2}$, MITSUAKI SUZUKI $^{3}$, HIROSHI TSUDA $^{4}$, \\ SATORU SAGAE ${ }^{5}$, YASUHIRO UDAGAWA ${ }^{6}$, KAZUO KUZUYA $^{7}$, JUNZO KIGAWA $^{8}$, SATOSHI TAKEUCHI ${ }^{9}$, \\ HITOSHI TSUDA ${ }^{10}$, TAKUYA MORIYA ${ }^{11}$ and TORU SUGIYAMA ${ }^{12}$
}

\begin{abstract}
${ }^{1}$ Department of Obstetrics and Gynecology, National Defense Medical College, Tokorozawa, Saitama 359-8513; ${ }^{2}$ Department of Obstetrics and Gynecology, Tohoku University, Sendai, Miyagi 980-8574; ${ }^{3}$ Department of Obstetrics and Gynecology, Jichi Medical College, Kawachi-gun, Tochigi 329-0498; ${ }^{4}$ Department of Obstetrics and Gynecology, Osaka City General Hospital, Osaka, Osaka 534-0021; ${ }^{5}$ Department of Obstetrics and Gynecology, Sapporo Medical University, Sapporo, Hokkaido 060-8556; ${ }^{6}$ Department of Obstetrics and Gynecology, Fujita Health University, Toyoake, Aichi 470-1192; ${ }^{7}$ Department of Gynecology, Aichi Cancer Center Hospital, Nagoya, Aichi 464-8681; ${ }^{8}$ Department of Obstetrics and Gynecology, Tottori University, Yonago, Tottori 683-8504; ${ }^{9}$ Department of Obstetrics and Gynecology, Kobe National Hospital, Kobe, Hyogo 554-0155; ${ }^{10}$ Department of Pathology II, National Defense Medical College, Tokorozawa, Saitama 359-8513; ${ }^{11}$ Pathology Laboratory of Central Clinical Facilities, Tohoku University, Sendai, Miyagi 980-8574; ${ }^{12}$ Department of Obstetrics and Gynecology, Iwate Medical University, Morioka, Iwate 020-8505, Japan
\end{abstract}

Received July 4, 2006; Accepted August 14, 2006

\begin{abstract}
Clear cell carcinoma (CCC) of the ovary has distinct characteristics showing resistance to conventional platinum-based regimen. Our aim was to evaluate the effects of combination therapy with irinotecan hydrochloride and cisplatin (CPT-P), comparing to regimen with paclitaxel and platinum (TP). We retrospective reviewed 172 patients with complete surgical staging procedures including lymphadenenctomy. Forty-six patients received CPT-P and 126 patients were treated with TP. Survival of the two groups was compared. Between CPT-P group and TP group, there was no significant difference in median age, performance status, FIGO stage, rate of optimal cytoreduction, and follow-up period. There was no significant difference in progressionfree survival of patients with stage I tumors $(\mathrm{p}=0.95)$ and suboptimally debulked stage II-IV tumors $(p=0.92)$. Although there was no significant difference of overall survival, progression-free survival of CPT-P group was significantly better than that of TP group in optimally debulked stage II-IV $(p=0.03)$. Multiple regression survival analysis revealed
\end{abstract}

Correspondence to: Dr Masashi Takano, ${ }^{13}$ Present address: Institute of Reproductive and Developmental Biology (IRDB), Imperial College of London, Hammersmith Hospital, Du Cane Road, London W12 0NN, UK

E-mail: m.takano@imperial.ac.uk

Key words: ovarian cancer, clear cell carcinoma, irinotecan hydrochloride, adjuvant chemotherapy, paclitaxel, multicentre, retrospective
CPT-P regimen $(\mathrm{p}=0.02)$ and residual tumor diameter $(\mathrm{p}<0.01)$ were both independent prognostic factors in stage II-IV tumors. The combination of CPT-P was shown to have a potential therapeutic benefit for advanced CCC of the ovary, especially for cases with optimal debulking surgery. However, this is a limited retrospective study, therefore we recommend that the CPT-P regimen be evaluated in a larger prospective study.

\section{Introduction}

Clear cell carcinoma (CCC) was initially termed as mesonephroid by Schiller in 1939 (1), and since 1973 it was strictly defined by World Health Organization as lesions characterized by clear cells growing in solid/tubular or glandular patterns as well as hobnail cells (2). Since then, many studies have identified the distinctive behavior of the tumors. The most distinctive difference is that patients with CCC of the ovary have poorer prognosis compared with those with other pathological types of epithelial ovarian carcinomas $(3,4)$. Additionally, CCC of the ovary was implied to show resistance to conventional platinum-based chemotherapy $(5,6)$. Recent studies confirmed the evidence in the analysis of measurable CCC patients: response was observed in 11-45\% with conventional platinum-based regimen, whereas patients with serous subtype showed a significantly higher response rate of $73-81 \%(7,8)$.

Combination with paclitaxel and platinum (TP), recognized as 'Gold standard' regimen for ovarian cancer, is now used to treat patients with all subtypes of ovarian neoplasms, but in measurable CCC cases treated with TP regimen, response was relatively low, ranging from 22 to $56 \%(9,10$; Enomoto T, et al, Proc Am Soc Clin Oncol 22: 447, abs. 1797, 2003). One 
report showed survival benefit of conventional chemotherapy with paclitaxel and platinum after complete surgery in CCC patients (11). However, the result from large series of CCC patients treated with paclitaxel and platinum showed no survival benefit compared with conventional platinum-based chemotherapy in both early and advanced cases (12).

Irinotecan hydrochloride, a semi-synthetic derivative of camptothecin, has additive and synergic effects in combination with cisplatin in vitro (13-15). The combination therapy with irinotecan hydrochloride and cisplatin (CPT-P) was reported to be effective for patients with various solid tumors. Especially, a large clinical trial revealed that CPT-P had significant activity for extensive small-cell lung cancer (16). Additionally, CPT-P has been reported to be effective in first-line and second-line chemotherapy for the treatment of CCC of ovary $(17,18)$. The aim of the present study was to evaluate the therapeutic activity of CPT-P and TP in a retrospective analysis.

\section{Patients and methods}

A retrospective review of the patients seen at ten Japanese hospitals from 1 January 1992 to 31 December 2003 was done. Of all the patients treated in those hospitals, the following patients were selected: a) patients who underwent complete surgical staging procedures including hysterectomy, bilateral salpingo-oophorectomy, peritoneal washing, omentectomy, pelvic lymphadenectomy and paraaortic lymphadenenctomy; b) patients whose tumor specimens were confirmed as CCC of the ovary by two pathologists in central pathologic review; c) patients treated with six courses of combination chemotherapy using irinotecan hydrochloride and cisplatin (CPT-P) or six courses of paclitaxel and platinum combination (TP); d) age $\leq 75$ years; e) Eastern Cooperative Oncology Group (ECOG) performance status (PS) of $\leq 2$; f) pretreatment leukocyte count $\geq 4000 / \mathrm{mm}^{3}$, platelet count $\geq 100000 / \mathrm{mm}^{3}$, hemoglobin $\geq 9.0 \mathrm{~g} / \mathrm{dl}$, serum creatinine $<1.5 \mathrm{mg} / \mathrm{dl}$, creatinine clearance $\geq 60 \mathrm{ml} / \mathrm{min}$, and GOT and GPT less than twice upper limit of normal at the hospitals; g) the study approved by the Committee on Ethics of each hospital.

One cycle of CPT-P regimen consisted of a drip infusion of $50-60 \mathrm{mg} / \mathrm{m}^{2}$ of cisplatin on day 1 and $50-60 \mathrm{mg} / \mathrm{m}^{2}$ of CPT-11 on days 1,8 and 15 , and one week off and it was repeated every 4 weeks. TP regimen consisted of a drip infusion of $175-180 \mathrm{mg} / \mathrm{m}^{2}$ of paclitaxel and $50-75 \mathrm{mg} / \mathrm{m}^{2}$ of cisplatin or carboplatin (AUC $=5-6)$.

Response was evaluated with CT or MR images at least every 2 cycles of chemotherapy in the patients with measurable disease. A complete response (CR) was defined as the complete disappearance of all detectable disease for at least 4 weeks. A partial response (PR) was defined as a $>50 \%$ decrease in tumor size for at least 4 weeks. Stable disease (SD) was defined as the absence of any significant change in measurable lesions for at least 4 weeks. Progressive disease (PD) was defined as the appearance of a new lesion or a $>25 \%$ increase in tumor size. Serum levels of tumor markers including CA125 were not used for response evaluation of chemotherapy in the present study.

The time to progression was defined as the interval from the date of primary surgery until the date of recurrence or tumor progression. Survival duration was determined as the time from the date of primary surgery until death or the date of last follow-up contact. Kaplan-Meier method was used for calculation of patient survival distribution. The significance of the survival distribution in each group was tested by a generalized Wilcoxon test and the log-rank test. The $\chi^{2}$ test and Student's t-test for unpaired data were used for statistical analysis. A p-value of $<0.05$ was considered statistically significant. The Stat View software ver. 5.0 (SAS Institution Inc., Cary, NC, USA) was used to analyze the data.

\section{Results}

In total, 46 cases with CPT-P regimen and 126 cases with TP regimen were enrolled in the present retrospective study. TP group included 118 cases treated with paclitaxel and carboplatin and 8 cases treated with paclitaxel and cisplatin. The characteristics of the patients are outlined in Table I. There was no significant difference in median age, performance status, FIGO stage, rate of optimal cytoreduction, and followup period between CPT-P group and TP group. Median age of all cases was 53 years (range, 27-75 years). CPT-P group included 24 patients (52\%) of stage I, $6(2 \%)$ in stage II, 13 (28\%) in stage III and $3(6 \%)$ in stage IV. In TP group, 72 cases $(56 \%)$ were in stage I, $15(12 \%)$ in stage II, $34(27 \%)$ in stage III and $5(4 \%)$ in stage IV. Optimal cytoreduction (residual tumor diameter $<1 \mathrm{~cm}$ ) with their initial surgery was achieved in 83\% (39/46) in CPT-P group and 83\% (104/126) in TP group, respectively. The patients with optimal cytoreductive surgery included 6 stage II, 7 stage III and 2 stage IV tumors in CPT-P group and 14 stage II, 16 stage III and 2 stage IV tumors in TP group. Median follow-up period was 28 months in CPT-P group and 27 months in TP group.

All patients who received CPT-P regimen were evaluable for toxicity. In 46 cases who received CPT-P regimen, 35 cases were treated with $50 \mathrm{mg} / \mathrm{m}^{2}$ of cisplatin and $60 \mathrm{mg} / \mathrm{m}^{2}$ of CPT- 11,7 cases with $60 \mathrm{mg} / \mathrm{m}^{2}$ of cisplatin and $60 \mathrm{mg} / \mathrm{m}^{2}$ of CPT-11, and 4 cases with $50 \mathrm{mg} / \mathrm{m}^{2}$ of cisplatin and $50 \mathrm{mg} /$ $\mathrm{m}^{2}$ of CPT-11, respectively. Hematological and non-hematological toxicities in all cases with CPT-P regimen are shown in Table II. The major toxicities were neutropenia and diarrhea. The incidences of grade 3 and 4 neutropenia were 22 and $7 \%$, respectively. Grade 3 nausea and grade 3 diarrhea was observed in 4 and $9 \%$ of all cases, respectively. CPT-11 was omitted in $12(26 \%)$ patients on days 8 or 15 because of toxicities, and $20 \%$ dose reduction of CPT-11 was documented in $10(22 \%)$ patients.

Response evaluation was assessed in the patients with suboptimal reduction; 22 cases of PT regimen and 7 cases of CPT-P regimen. The patients treated with PT included $1(5 \%)$ CR, 6 (27\%) PR, 3 (14\%) SD and 12 (55\%) PD. CPT-P group consisted of $3(43 \%)$ PR, 2 (29\%) SD and 2 (29\%) PD, respectively. Response was observed in 7 (32\%) of 22 cases in TP group and 3 (43\%) of 7 cases in CPT-P group. The rates of non-PD patients were $71 \%$ (5 of 7 cases) in CPT-P group and $45 \%$ (10 of 22 cases) in TP group, respectively ( $\mathrm{p}=0.047)$.

Two-year and progression-free and overall survival in stage I tumors was 77 and $92 \%$ in CPT-P group and 78 and $94 \%$ in TP group, respectively. There were no significant survival differences in progression-free survival (Fig. 1A, $\mathrm{p}=0.95)$ and overall survival $(\mathrm{p}=0.40)$ in stage I tumors. 
Table I. Characteristics of the patients.

\begin{tabular}{|c|c|c|c|c|c|}
\hline & \multicolumn{2}{|c|}{$\begin{array}{l}\text { Irinotecan plus cisplatin } \\
(\%)\end{array}$} & \multicolumn{2}{|c|}{$\begin{array}{l}\text { Paclitaxel plus platinum } \\
\qquad(\%)\end{array}$} & P-value \\
\hline Patients & \multicolumn{2}{|c|}{46} & \multicolumn{2}{|c|}{126} & \\
\hline Median age (years) (range) & \multicolumn{2}{|c|}{$52(32-69)$} & \multicolumn{2}{|c|}{$53(27-75)$} & 0.85 \\
\hline \multicolumn{5}{|l|}{ Performance status } & 0.17 \\
\hline 0 & 26 & $(57)$ & 85 & $(67)$ & \\
\hline 1,2 & 20 & (43) & 41 & (33) & \\
\hline \multicolumn{5}{|l|}{ FIGO stage } & 0.88 \\
\hline I & 24 & $(52)$ & 72 & $(57)$ & \\
\hline II & 6 & (13) & 15 & (12) & \\
\hline III & 13 & (28) & 34 & $(27)$ & \\
\hline IV & 3 & $(7)$ & 5 & $(4)$ & \\
\hline \multicolumn{5}{|l|}{ Primary surgery } & 0.32 \\
\hline Optimal reduction & 39 & $(85)$ & 104 & (83) & \\
\hline Suboptimal reduction & 7 & (15) & 22 & $(17)$ & \\
\hline \multicolumn{5}{|l|}{ Follow-up period (months) } & 0.43 \\
\hline Median & \multicolumn{2}{|c|}{28} & \multicolumn{2}{|c|}{27} & \\
\hline Range & \multicolumn{2}{|c|}{$6-83$} & \multicolumn{2}{|c|}{$3-73$} & \\
\hline
\end{tabular}

Table II. Hematological and non-hematological toxicity of combination chemotherapy of irinotecan hydrochloride and cisplatin for clear cell carcinoma of ovary.

\begin{tabular}{|c|c|c|c|c|c|}
\hline & \multicolumn{5}{|c|}{ Grade of toxicities } \\
\hline & $\begin{array}{c}0 \\
\mathrm{n}(\%)\end{array}$ & $\begin{array}{c}1 \\
\mathrm{n}(\%)\end{array}$ & $\begin{array}{c}2 \\
\mathrm{n}(\%)\end{array}$ & $\begin{array}{c}3 \\
\mathrm{n}(\%)\end{array}$ & $\begin{array}{c}4 \\
\mathrm{n}(\%)\end{array}$ \\
\hline \multicolumn{6}{|l|}{ Hematological } \\
\hline Neutropenia & 4 (9) & 18 (39) & 11 (24) & $10(22)$ & $3(7)$ \\
\hline Anemia & $14(30)$ & $20(43)$ & $10(22)$ & $1 \quad(2)$ & 1 (2) \\
\hline Thrombocytopenia & 41 (89) & 2 (4) & $1 \quad(2)$ & $1 \quad(2)$ & 1 (2) \\
\hline \multicolumn{6}{|l|}{ Non-hematological } \\
\hline Nausea & $1 \quad(2)$ & $23(50)$ & 20 & $2 \quad(4)$ & - \\
\hline Fatigue & $25(54)$ & $14(30)$ & 7 (15) & $0 \quad(0)$ & $0 \quad(0)$ \\
\hline Diarrhea & $12(26)$ & $21(46)$ & $9(20)$ & $4 \quad(9)$ & $0 \quad(0)$ \\
\hline
\end{tabular}

Patients with suboptimal cytoreduction surgery included 7 cases of CPT-P group and 22 cases of TP group. In these patients with suboptimal reduction, median survival was 10 months in CPT-P group and 12 months in TP group, and there were no significant differences in progression-free survival (Fig. 1B, $\mathrm{p}=0.92)$ and overall survival $(\mathrm{p}=0.82)$.

In stage II-IV tumors, optimal reduction at their initial surgery was achieved in $15(68 \%)$ of 22 patients in CPT-P group and $32(59 \%)$ of 54 patients in TP group. Among optimally debulked patients, CPT-P group included 10 cases $(67 \%)$ of no residual tumor and $5(33 \%)$ cases of tumor diameter $<1 \mathrm{~cm}$, and TP group consisted of 24 cases $(75 \%)$ of no residual tumor and 8 cases $(25 \%)$ of tumor diameter $<1 \mathrm{~cm}$. There was no significant distribution difference of residual tumor diameter in optimally debulked patients between CPT-P and TP group ( $\mathrm{p}=0.55)$.

Progression-free survival of CPT-P group was significantly better than that of TP group in the group with stage II-IV optimal cytoreduction (Fig. 2, $\mathrm{p}=0.03$ ). Two-year progressionfree survival was $86 \%$ in CPT-P group and $44 \%$ in TP group, respectively. Median progression-free survival of TP group was 15 months. There was no significant difference in overall 
A

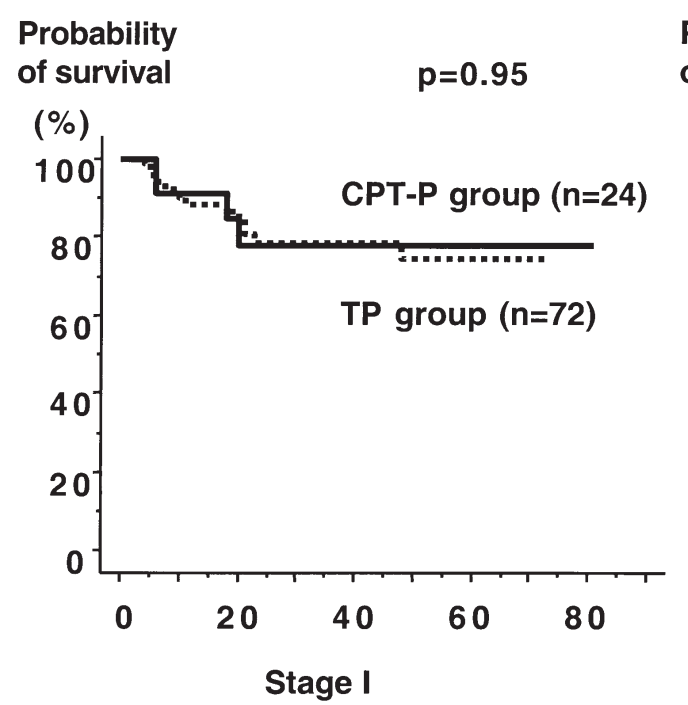

B
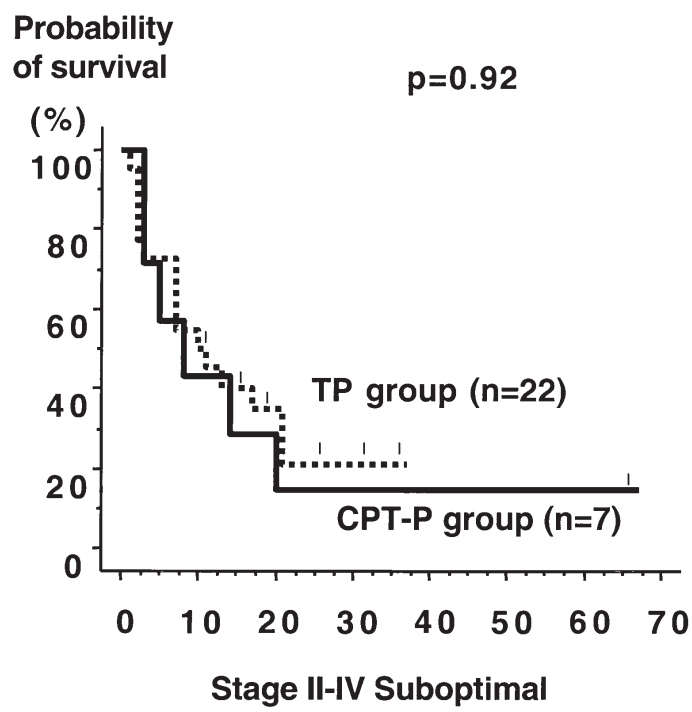

Figure 1. Kaplan-Meier curve comparing the progression-free survival of stage I patients (A) and stage II-IV patients with suboptimal debulking surgery (B) according to adjuvant chemotherapy. No significant difference was observed in patients with stage I ( $\mathrm{p}=0.95$ ), and those with stage II-IV suboptimal debulking patients $(\mathrm{p}=0.92)$.

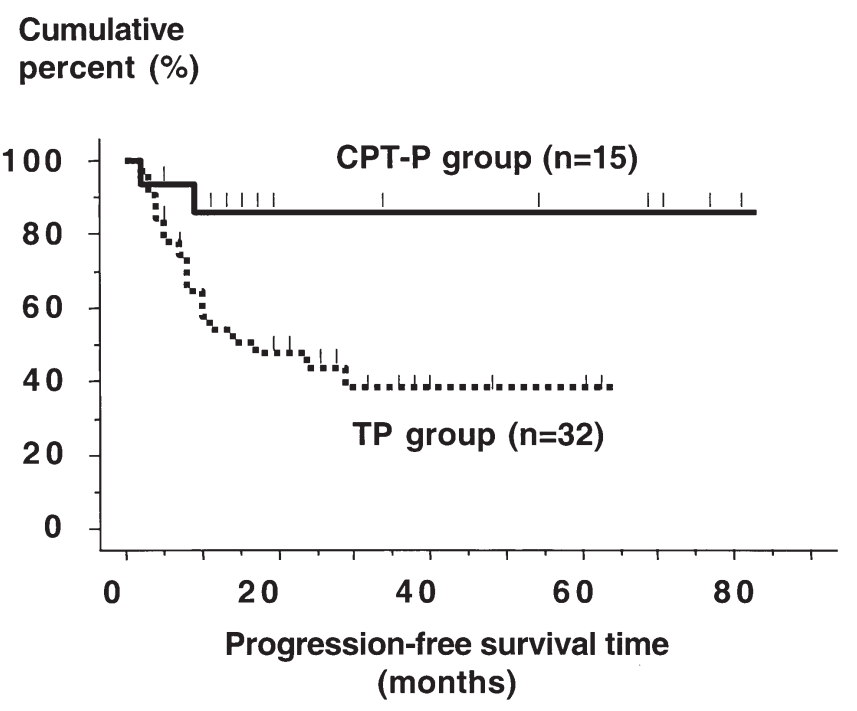

Figure 2. Kaplan-Meier curve comparing the progression-free survival of the stage II-IV patients with optimal debulking surgery according to adjuvant chemotherapy. The survival of the patients with combination with irinotecan hydrochloride and cisplatin (CPT-P) was significantly better than that with paclitaxel and platinum (TP) $(\mathrm{p}=0.03)$. Two-year progression-free survival was $86 \%$ in CPT-P group and $44 \%$ in TP group and median progression-free survival time was 13 months in CPT-P group and 11 months in TP group, respectively.

survival of optimally debulked stage II-IV patients according to two regimens $(\mathrm{p}=0.14)$.

In stage II-IV tumors with optimal reduction, two parameters were independent prognostic factors for progressionfree survival as determined by multivariate analysis: residual tumor diameter $<1 \mathrm{~cm}$ (hazard ratio, 3.77; $<<0.01$ ); paclitaxel and platinum (hazard ratio, 6.454; p=0.02) (Table III). Age, performance status, and FIGO stage were not significant prognostic factors.

\section{Discussion}

In a previous study with CPT-P regimen for ovarian cancer using $70 \mathrm{mg} / \mathrm{m}^{2}$ of cisplatin on day 1 and $60 \mathrm{mg} / \mathrm{m}^{2}$ of irinotecan hydrochloride on days 1,8 and 15 , toxicities more than grade 3 was observed in $52-70 \%$ for neutropenia and $4-10 \%$ for diarrhea $(17,19)$. Japanese large clinical trial using $60 \mathrm{mg} / \mathrm{m}^{2}$ of cisplatin and $60 \mathrm{mg} / \mathrm{m}^{2}$ of irinotecan hydrochloride for patients with lung cancer (16) showed high abundance of grade 3-4 toxicities compared with the present study. The lower rates of grade 3-4 toxicities might be explained by a large proportion of patients who received a lower dose (50 $\mathrm{mg} / \mathrm{m}^{2}$ ) of irinotecan hydrochloride. A variety of single nucleotide polymorphisms (SNPs) in human UDP-glucuronosyltransferase could cause a different toxicity profile in patients treated with irinotecan hydrochloride $(20,21)$. A variety of SNPs in specific genes might cause the diseasespecific toxicity profiles. In the present study, the most common grade 3-4 adverse effect was neutropenia observed in $28 \%$ of patients, but it was reversible in all cases. Diarrhea more than grade 3 was observed in $4(9 \%)$ patients and it was reversible with conservative treatment. It was suggested that CPT-P regimen was relatively safe and well-tolerated in firstline chemotherapy in $\mathrm{CCC}$ patients.

CCC of the ovary has been suggested to lack sensitivity compared to conventional platinum-based chemotherapy $(3,4,7)$. As combination chemotherapy of TP regimen is now established as 'Gold standard' regimen for epithelial ovarian cancer $(22,23)$, the regimen is widely used for all histological sub-types of ovarian tumors. Some reports indicated survival benefit of TP therapy compared with platinum-based chemotherapy in stage I CCC disease combined with complete surgical staging procedures (11) and stage III, IV tumors (9). However, a recent study including 254 patients with complete surgical staging revealed that there was no significant survival 
Table III. Multiple regression survival analysis for stage II-IV patients with optimally debulked clear cell carcinoma of the ovary.

\begin{tabular}{lcc}
\hline Variables & Hazard ratio & $\begin{array}{c}95 \% \text { confidence } \\
\text { interval }\end{array}$ \\
\hline
\end{tabular}

Age (years)

$<50$

$>51$

Performance status

0

1,2

1.08

FIGO stage

II

III

IV

1.60

3.04

Residual tumor

None

$<1 \mathrm{~cm}$

Chemotherapy

Irinotecan hydrochloride and cisplatin

Paclitaxel and platinum
1

$1.42 ; 9.98$

1

6.454
$0.40 ; 2.90$

$0.32 ; 8.00$

$0.55 ; 16.67$

0.88

$1.40 ; 29.86$ benefit with TP regimen compared with conventional platinumbased chemotherapy in either early or advance staged patients (12). So far, no anti-cancer agents have been established as a standard regimen for CCC. From view of molecular profiling, CCC is recognized as a completely different category from tumors of other histological subtypes $(24,25)$. These distinct molecular characteristics might support the necessity of another approach for the treatment of CCC of the ovary.

CPT-P regimen, initially introduced as a treatment of platinum-refractory ovarian cancer (19), showed moderate activity for first-line chemotherapy of CCC (17). In vitro study suggested that irinotecan hydrochloride as well as paclitaxel was the candidate for anti-neoplastic agents for CCC (26). The present study shows that response rate of CPT-P was almost the same as TP. High abundance of SD patients in CPT-P regimen, acting as 'tumor-dormancy' effects, could possibly lead to better progression-free survival in patients with stage II-IV optimal cytoreductive surgery. The significance of CPT-P regimen was also identified as a favorable prognostic factor with multivariate analysis as well as absence of residual tumor. In addition to the toxicity profile, the efficacy of CPT-P was considered to be satisfactory for the treatment for CCC of the ovary.

Irinotecan hydrochloride was shown to have higher activity than conventional platinum-based regimen for adjuvant setting in combination with mitomycin C (27). Combination chemotherapy including irinotecan hydrochloride was suggested to have a potential anti-tumor effect against CCC of the ovary. CCC of ovary has been reported to have a distinct molecular characteristics as well as a distinctive clinical behavior. Targeting therapy for CCC-specific molecular markers such as hepatocyte nuclear factor-1 ß (28) or $\mathrm{ABCF} 2$, a member of ATP-binding cassette gene superfamily (29), could possibly be another strategy for the treatment of CCC of the ovary. Although CPT-P could be a candidate regimen showing some efficacy, a large-scale prospective trial is needed to confirm these observations.

\section{Acknowledgements}

We are indebted to Drs T. Kita (National Defense Medical College), M. Sakuma (Tohoku University), Y. Saga (Jichi Medical College), M. Sugimura (Sapporo Medical University), K. Hasegawa (Fujita Health University), M. Shimada (Tottori University), A. Yoshizaki (Iwate Medical University) who allowed us to review the patients' medical charts.

\section{References}

1. Schiller W: Mesonephroma ovarii. Am J Cancer 35: 1-21, 1939.

2. Serov SF, Scully RE and Sobin LH: International histologic classification of tumors. In: Histologic Typing of Ovarian Tumors. World Health Organization, Geneva, No. 9, 1973.

3. O'Brien ME, Schofield JB, Tan S, Fryatt I, Fisher C and Wiltshaw E: Clear cell epithelial ovarian carcinoma cancer (mesonephroid): bad prognosis only in early stages. Gynecol Oncol 49: 250-254, 1993.

4. Omura GA, Brady MF, Homesley HD, Yordan E, Major FJ, Buchsbaum HJ and Park RC: Long-term follow-up prognostic factor analysis in advanced ovarian carcinoma: the Gynecologic Oncology Group experiences. J Clin Oncol 9: 1138-1150, 1991.

5. Goff BA, Sainz de la Cuesta R, Muntz HG, Fleischhacker D, Ek M, Rice LW, Nikrui N, Tamimi HK, Cain JM, Greer BE and Fuller AF Jr: Clear cell carcinoma of the ovary: a distinct histologic type with poor prognosis and resistance to platinumbased chemotherapy in stage III disease. Gynecol Oncol 60: 412-417, 1996. 
6. Recio FO, Piver MS, Hempling RE and Driscoll DL: Lack of improved survival plus increase in thromboembolic complications in patients with clear cell carcinoma of the ovary treated with platinum versus non-platinum-based chemotherapy. Cancer 78: 2157-2163, 1996.

7. Sugiyama T, Kamura T, Kigawa J, Terakawa N, Kikuchi Y, Kita T, Suzuki M, Sato I and Taguchi K: Clinical characteristics of clear cell carcinoma of the ovary. Cancer 88: 2584-2589, 2000.

8. Pectasides D, Fountzilas G, Aravantinos G, Kalofonos C, Efstathiou H, Farmakis D, Skarlos D, Pavlidis N, Economopoulos T and Dimopoulos MA: Advanced stage clearcell epithelial ovarian cancer: the Hellenic cooperative oncology group experience. Gynecol Oncol (In press).

9. Ho CM, Huang YJ, Chen TC, Huang SH, Liu FS, Chang Chien CC, Yu MH, Mao TL, Wang TY and Hsieh CY: Puretype clear cell carcinoma of the ovary as a distinct histological type and improved survival in patients treated with paclitaxelplatinum-based chemotherapy in pure-type advanced disease. Gynecol Oncol 94: 197-203, 2004.

10. Utsunomiya H, Akahira J, Tanno S, Moriya T, Toyoshima M, Niikura $\mathrm{H}$, Ito K, Morimura $\mathrm{Y}$, Watanabe $\mathrm{Y}$ and Yaegashi N: Paclitaxel-platinum combination chemotherapy for advanced or recurrent ovarian clear cell adenocarcinoma: a multicenter trial. Int J Gynecol Cancer 16: 52-56, 2006.

11. Ho CM, Chien TY, Shih BY and Huang SH: Evaluation of complete surgical staging with pelvic and para-aortic lymphadenectomy and paclitaxel plus carboplatin chemotherapy for improvement of survival in stage I ovarian clear cell carcinoma. Gynecol Oncol 88: 394-399, 2003.

12. Takano M, Kikuchi Y, Yaegashi N, Kuzuya K, Ueki M, Tsuda H, Suzuki M, Kigawa J, Takeuchi S, Tshuda H, Moriya T and Sugiyama T: Clear cell carcinoma of the ovary: a retrospective multicentre experience of 254 patients with complete surgical staging. Br J Cancer 94: 1369-1374, 2006.

13. Kano Y, Suzuki K, Akutsu M, Suda K, Inoue Y, Yoshida M, Sakamoto S and Miura Y: Effects of CPT-11 in combination with other anticancer agents in culture. Int J Cancer 50: 604-610, 1992.

14. Minagawa $\mathrm{Y}$, Kigawa J, Ishihara $\mathrm{H}$, Itamochi $\mathrm{H}$ and Terakawa $\mathrm{N}$ : Synergistic enhancement of cisplatin cytotoxicity by $\mathrm{SN}-38$, an active metabolite of CPT-11, for cisplatin-resistant HeLa cells. Jpn J Cancer Res 85: 966-971, 1994.

15. Fukuda M, Nishio K, Kanzawa F, Ogasawara H, Ishida T, Arioka H, Bojanowski K, Oka M and Saijo N: Synergistic enhancement of cisplatin cytotoxicity by $\mathrm{SN}-38$, an active metabolite of CPT-11, for cisplatin-resistant HeLa cells. Cancer Res 56: 789-793, 1996.

16. Noda K, Nishiwaki Y, Kawahara M, Negoro S, Sugiura T, Yokoyama A, Fukuoka M, Mori K, Watanabe K, Tamura T, Yamamoto S and Saijo N; Japan Clinical Oncology Group: Irinotecan plus cisplatin compared with etoposide plus cisplatin for extensive small-cell lung cancer. N Eng J Med 346: 85-91, 2002.

17. Adachi S, Ogasawara T, Yamasaki N, Shibahara H, Kanazawa R, Tsuji Y, Takemura T and Koyama K: A pilot study of CPT-11 and cisplatin for ovarian clear cell adenocarcinoma. Jpn J Clin Oncol 29: 434-437, 1999.

18. Kita T, Kikuchi Y, Kudoh K, Takano M, Goto T, Hirata J, Tode T and Nagata I: Exploratory study of effective chemotherapy to clear cell carcinoma of the ovary. Oncol Rep 7: 327-331, 2000.
19. Sugiyama T, Yakushiji M, Nishida T, Ushijima K, Okura N, Kigawa J and Terakawa N: Irinotecan (CPT-11) combined with cisplatin in patients with refractory or recurrent ovarian cancer. Cancer Lett 128: 211-218, 1998.

20. Jinno H, Saeki M, Saito Y, Tanaka-Kagawa T, Hanioka N, Sai K, Kaniwa N, Ando M, Shirao K, Minami H, Ohtsu A, Yoshida T, Saijo N, Ozawa S and Sawada J: Functional characterization of human UDP-glucuronosyltransferase 1A9 variant, D256N, found in Japanese cancer patients. J Pharmacol Exp Ther 306: 688-693, 2003.

21. Sai K, Saeki M, Saito Y, Ozawa S, Katori N, Jinno H, Hasegawa R, Kaniwa N, Sawada J, Komamura K, Ueno K, Kamakura S, Kitakaze M, Kitamura Y, Kamatani N, Minami H, Ohtsu A, Shirao K, Yoshida T and Saijo N: UGT1A1 haplotypes associated with reduced glucuronidation and increased serum bilirubin in irinotecan-administered Japanese patients with cancer. Clin Pharmacol Ther 75: 501-515, 2004.

22. McGuire WP, Hoskins WJ, Brady MF, Kucera PR, Partridge EE, Look KY, Clarke-Pearson DL and Davidson M: Cyclophosphamide and cisplatin compared with paclitaxel and cisplatin in patients with stage III and stage IV ovarian cancer. N Eng J Med 334: 1-6, 1996.

23. Bookman MA, Greer BE and Ozols RF: Optimal therapy of advanced ovarian cancer: carboplatin and paclitaxel vs. cisplatin and paclitaxel (GOG158) and an update on GOG0182-ICON5. Int J Gynecol Cancer 13: 735-740, 2003.

24. Zorn KK, Bonome T, Gangi L, Chandramouli GV, Awtrey CS, Gardner GJ, Barrett JC, Boyd J and Birrer MJ: Gene expression profiles of serous, endometrioid and clear cell subtypes of ovarian and endometrial cancer. Clin Cancer Res 15: 6422-6430, 2005.

25. Marquez RT, Baggerly KA, Patterson AP, Liu J, Broaddus R, Frumovitz M, Atkinson EN, Smith DI, Hartmann L, Fishman D, Berchuck A, Whitaker R, Gershenson DM, Mills GB, Bast RC $\mathrm{Jr}$ and $\mathrm{Lu} \mathrm{KH}$ : Patterns of gene expression in different histotypes of epithelial ovarian cancer correlate with those in normal fallopian tube, endometrium, and colon. Clin Cancer Res 11: 6116-6126, 2005 .

26. Itamochi H, Kigawa J, Sultana H, Iba T, Akeshima R, Kamazawa S, Kanamori Y and Terakawa N: Sensitivity to anticancer agents and resistance mechanisms in clear cell carcinoma of the ovary. Jpn J Cancer Res 93: 723-728, 2002.

27. Nishino K, Aoki Y, Amikura T, Obata H, Sekine M, Yahata T, Fujita $\mathrm{K}$ and Tanaka K: Irinotecan hydrochloride (CPT-11) and mitomycin $\mathrm{C}$ as the first line chemotherapy for ovarian clear cell carcinoma. Gynecol Oncol 97: 893-897, 2005.

28. Tsuchiya A, Sakamoto M, Yasuda J, Chuma M, Ohta T, Ohki M, Yasugi T, Taketani Y and Hirohashi S: Expression profiling in ovarian clear cell carcinoma: identification of hepatocyte nuclear factor-1 beta as a molecular marker and a possible molecular target for therapy of ovarian clear cell carcinoma. Am J Pathol 163: 2503-2512, 2003.

29. Tsuda H, Ito YM, Ohashi Y, Wong KK, Hashiguchi Y, Welch WR, Berkowitz RS, Birrer MJ and Mok SC: Identification of overexpression and amplification of $\mathrm{ABCF} 2$ in clear cell ovarian adenocarcinoma by cDNA microarray analysis. Clin Cancer Res 11: 6880-6888, 2005. 